\title{
Archives of
}

\section{Business Administration and Management}

\section{A Digital Strategy for Enhancing the Customer Journey via a Customer-Centric Website}

\author{
John Michael York ${ }^{1,2^{*}}$ \\ ${ }^{1}$ Rady School of Management, University of California, San Diego, San Diego, CA, USA \\ ${ }^{2}$ Orfalea College of Business, California Polytechnic State University, San Luis Obispo, San Luis Obispo, CA, USA
}

"Corresponding author: John Michael York, Rady School of Management, University of California, San Diego, San Diego, CA, USA. Tel: +1-8052382485; Email: j1york@ucsd.edu.

Citation: York JM (2018) A Digital Strategy for Enhancing the Customer Journey via a Customer-Centric Website. Arch Bus Adm Manag: ABAM-122. DOI: 10.29011/ABAM-122. 100022

Received Date: 28 October 2018; Accepted Date: 26 November 2018; Published Date: 05 December 2018

\begin{abstract}
The growth of social media has changed the landscape of digital marketing. With social media over the last decade, this dynamic has changed to that of a permissive or "Pull" strategy, rather than a more traditional approach involving "Push" approach. This discussion will examine the following areas to explore this customer-centricity dynamic: (1) why companies need to shift web marketing to that of a customer-centric website; (2) what features and functionality of a customer-centric website are required; and (3) how customer-centric website content influences consumer buying process.
\end{abstract}

Keywords: Customer-Centric; Consumer Journey; Digital Marketing; Search Engine Optimization (SEO); Search Engine Report Page (SERP); Website Optimization

\section{Introduction}

The growth of social media has changed the landscape of digital marketing. However, many business owners and marketers fail to define a strategy for their digital and social approaches, or, if so, continue to use a "Push" strategy to engage their target audience(s). In essence, they are in love with their product or "product-centric," rather than being "customer-centric" in their approach to digital and social media. With the growth of social media over the last decade, this dynamic has changed to that of a permissive or "Pull" strategy, rather than a more traditional approach involving "Push."

This paper will examine the following areas to explore this customer-centricity dynamic: (1) why companies need to shift web marketing to that of a customer-centric website; (2) what features and functionality of a customer-centric website are required; and (3) how customer-centric website content influences the consumer buying process.

\section{Why the Need to Change}

\section{(the Times Are a Changing)}

To understand the need for change, one must start with an understanding of what is customer-centric. According to the business dictionary, being customer-centric involves an approach to doing business with your customer in a way that provides a positive customer experience before, during, and after the sale to drive repeat business, customer loyalty and profits [1]. The American Marketing Association refines this a little further in that it is beyond customer feedback or satisfaction- to understand current customer needs and ensure that there are right internal strategies, processes, and marketing to satisfy them [2].

For many years, many marketers believe all they need is to have a website and have made this platform product- or companyoriented, rather than customer-focused. They forget who they are in business for- the customer. It is about "Push, Push, and Push." Much of this mentality emanates from the use of more traditional media (e.g., print, radio, television) to reach large audiences. It also comes from the strong desire to control the marketing message and that they interrupt our attention to deliver the message (why we see more and more outrageous commercials on television). I 
have seen entrepreneurs, small businesses, and marketers continue to employ this approach, both in my consulting practice and in my marketing projects classes to both undergraduate and graduate students at Orfalea College of Business and startups at University of California, San Diego. Unfortunately, this type of behavior is far from being customer centric.

Over the last fifteen years, the internet has changed this dynamic dramatically. The availability of broadband service and higher capacity cellular service throughout the developed world has created for an open, interactive, 24/7 global marketplace where sales can be direct with the customer. This marketplace is no longer involves one-way communication, but rather two-way (or multiparty) dialogue with and among customers.

With this hyper-interactive (and hypercompetitive) environment, the day of the static website no longer exists. For many years, companies would post their firms' and products' information. Some would include a shopping cart, and that was it. This approach will not suffice today.

In this new era of marketing, marketers have to be customercentric with their websites. Why? It is about understanding "man," woman," or "human") and "machine." The first reality is to understand the "man" ("woman" or "human"). Customer behavior has changed tremendously, especially in the customer journey, this past decade due to infrastructure, device, online platforms, and search algorithms. Hence, the first place a customer goes to when having a need is to the web and types in a phrase in search of what he/she is seeking. One's search intent can be navigational, informational, or transactional. Many times, the customer is just seeking information or education to start the journey. Later, as the customer becomes more involved with the search process, he/she evaluates various alternatives, as he/she is comparing features, benefits, and pricing. Finally, as the customer is ready for a decision to buy, he/she will seek triggers to promote the choice to acquire the product or sign up for a consultation or another type of engagement (e.g., newsletter, webinar). David Meerman Scott provides such examples in his book The New Rules of Marketing and PR (e.g., researching a racing bike, buying a wooden surfboard, and seeking out a vacation for his family) [3]. As a personal example, my family recently followed such a path in adopting two new dogs and purchasing our current automobiles this past summer. In essence, we all as consumers are moving through this journey and on the web as part of our purchasing habits and also in making sure that we are taken care of after the purchase. This behavior is driving the dynamic.

Secondly, there is the machine. With the advent of highly efficient and intelligent search engines, such as Google and Bing, these engines play a significant role whether a firm ends up on page 1 of a Search Engine Report Page (SERP). These search algorithms respond to the user's search behavior and call up the most relevant websites. These algorithms do evaluate one's site, as to its content, its keywords, linking (back and outbound), and its infrastructure. If one has optimized the quality of the site and its functionality, then the search engines will reward a company with a high SERP posting or a lower cost per click charge for bidding for AdWords.

Therefore, to be competitive, a company needs to be found on page 1 of a SERP by its customers. To achieve this objective, it needs to optimize its site. Optimizing one's website requires that it be customer-centric, meaning that it contains content within and links that are authentic, of high interest, and relevant to the customer. This way the customer can find one's business on page 1 of his/her search. Then, to the customer visiting the site, he/she needs to feel that the site makes the individual's journey easy to allow him/her to engage and acquire the offered product, service or offering (e.g., free sign up for a newsletter or white paper, optin for future communications). The website needs to keep this journey in mind to make the interaction, on whatever the platform (web, tablet, phone), is comfortable and enjoyable. The experience of the design of the site and functionality needs to keep in mind how the customer engages. Finally, the site needs to bring the customer experience the desire to stay with your company due to strong post-purchase experience through reliable customer service. In many ways, customer centricity in the website should reflect the brand, which as Jerimiah Gardner, author of The Lean Brand, characterizes as the relationship between your company/product and the customer, both functionally and emotionally [4].

\section{What Features and Functionality \\ (SEO, Content, Structure, Features, \& Function)}

To have a customer-centric website, one needs to keep in mind the customer and the customer journey (before, during, and after) as a priority (Figure 1). The design process requires the creator to put him/herself in the customer's place to develop a site that: (1) a customer can easily find; (2) provides relevant content to the buying decision; (3) is user-friendly; and (4) provides a mechanism for ongoing post-purchase support. 


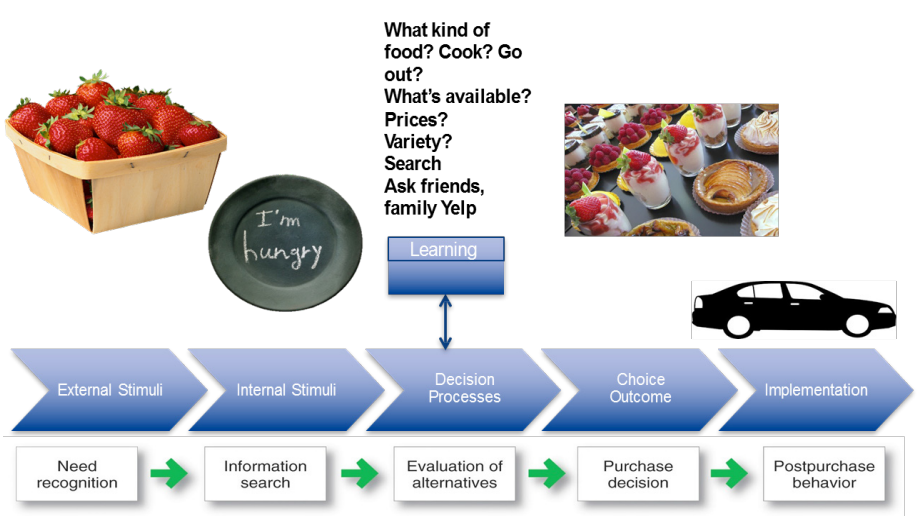

(Image Courtesy of Katheryn Gorges, Social Marketing Diva)

Figure 1: The Customer Journey [5].

To be easily found, the website needs to be optimized, both in its content and its structure. These factors allow for allowing the site to be picked up on page 1 of a SERP. Search engine optimization (SEO) practices allow for this outcome with organic (non-paid) search. Two key pieces are keywords and links. Pages should include keywords that are relevant to the customer search, not just to the company and its product. Therefore, keyword research is critical and should start with the customer journey in mind, followed by search engine fill-ins, searching of competitive sites, and accompanied by culling with keyword/Ad word tools. The designer of the content needs to keep this critical piece in mind. Also, the keywords need to be mentioned on the page and in the site multiple times. One should include these in the site name (if possible), meta description, and URL (if possible). Notably, it is essential that one purposefully employ keywords. If a firm tries to stuff the keywords (e.g., careless use and overcrowding of keywords used in a way that is not natural), it takes on substantial risks having the search engine providers identify itself as a "Black Hat" practitioner by the search engine providers. Addition, major headlines, and subheads should include these keywords.

However, keywords are not the be-all and end-all for SEO. The site needs to provide genuinely relevant content to address its customer and his/her needs by supporting the "I" or an informational portion of the journey. This content can involve text, audio, figures, photos, and video. While recent trends are moving less textual content, an ongoing blog is a great way to optimize the content. Finally, the content needs to be dynamic, as the search engines are continually monitoring and evaluating your site and its content. They reward those who regularly update on a regular basis (e.g., weekly). Therefore, for organic search, a company continually needs to keep the customer in mind relative to their search intent and needs to deliver the content that will lead the customer to the site. The bottom line is that a firm, along with its management and marketing staff, needs to know its audience and its needs.
Complementing the content piece is that of the site architecture. In essence, a company needs to make sure its sites are technically optimized. Since search engines "see" your site, a firm needs to engineer a website to increase organic search visibility, which the search engine desires as well as your customer who is looking for your firm.

Table 1 highlights several significant technical attributes that are essential to optimizing SEO. Lorrie Thomas also emphasizes these technical points in her book, The McGraw-Hill 36-Hour Course: Online Marketing [6]. The site needs to go beyond aesthetics and design, one area with which many firms and agencies become over-enamored and, hence, fail to consider the customer experience and site's technical functionality to engage the visitor optimally. Of note are schema and site loading speed.

\begin{tabular}{|c|c|}
\hline - XML sitemap & - Clean URLs \\
\hline $\begin{array}{l}\text { - Robots.txt file configuration } \\
\text { - } \quad \text { Page speed optimization }\end{array}$ & $\begin{array}{l}\text { - Google Analytics } \\
\text { implementation }\end{array}$ \\
\hline - Code validation (W3C) & $\begin{array}{l}\text { Responsive on multiple } \\
\text { platforms (mobile/tablet) }\end{array}$ \\
\hline $\begin{array}{l}\text { - Setup custom } 404 \text { error } \\
\text { page } \\
\text { - Schema markup }\end{array}$ & $\begin{array}{l}\text { Google Search Console } \\
\text { (Webmaster Tools) } \\
\text { verification and analysis }\end{array}$ \\
\hline $\begin{array}{l}\text { Fixed broken links and } \\
\text { broken images }\end{array}$ & $\begin{array}{l}\text { Optimization of tags } \\
\text { (Title, Meta, Heading, } \\
\text { Image alt, Link title }\end{array}$ \\
\hline $\begin{array}{l}\text { - Elimination of duplicate } \\
\text { content }\end{array}$ & - Internal anchor text \\
\hline
\end{tabular}

Table 1: Website/Landing Page Technical Elements to Enhance Search Engine Optimization [7].

Of these items, schema marks up, along with page speed optimization and responsiveness on multiple platforms, are critical. The organization of the site and the speed of downloading a site can significantly influence initial bounce rate and a poor first impression to the customer who persists. Therefore, the page should load quickly. With the advent of technology with multiple platforms, it is imperative the site be mobile or tablet friendly. It should load just as fast as on a desktop and be able to be navigated just as quickly. The pages need to be responsive to customers, who are using mobile platforms more than a web-based one. Furthermore, with the Accelerate Mobile Pages (AMP) project to optimize the mobile loading and experience, sites need to consider such parameters.

My colleagues of Gerson and Associates, Inc. and Marketing Mondays faculty at Evonexus in San Diego, Randy Gerson and Chris d'Eon, highlight the basics around an efficient home or 
landing page (Figure 2) [8]. They emphasize that these pieces should be a straightforward and include: (1) headline (attention); (2) subhead-benefit; (3) copy-explain clearly, not cutely and not too long; (4) testimonials; (5) "call-to-action"; (6) links; and (7) video/photo (with a benefit caption with a photo). They also point out that the site should be informative, helpful, personal, relevant, and represent your brand. The note the site information if it is discussing the product should always bring in the benefits. They recommend the features, advantage, and benefit (FAB) approach. In essence, what the features and advantages mean to the customer (and from the customer's perspective). They also emphasize linking to your social sites by installing plugins for these sites and make them easy to find on every page. Finally, they advise tying in one's social sites to connect to the landing page with appropriate "call-to-action" buttons and links at these social sites (Figure 3) to guide along the customer and to nurture leads.

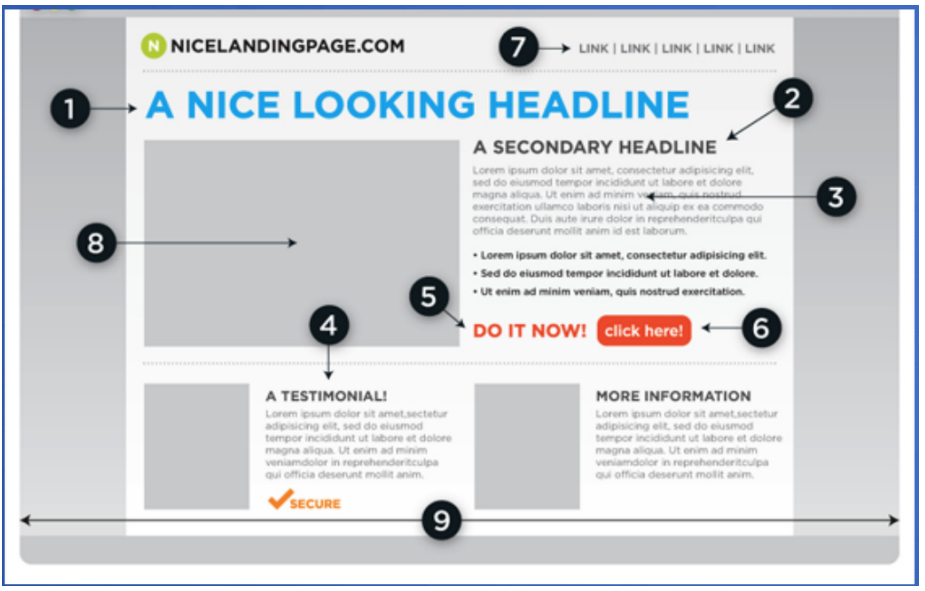

1) Headline (attention); 2) Subhead (benefit); 30 Copy (explain clearly, not cutely); 4.)Testimonials; 5) Urgency; 6) “““call-to-action”; 7) Links (if necessary); 8) Video/Photo (if the photo, please have benefit caption). (Image Courtesy of Randy Gerson and Chris dEon, Gerson and Associates, 2018) [4]

Figure 2: Key Elements for an Effective Home (or Landing) Page [8]

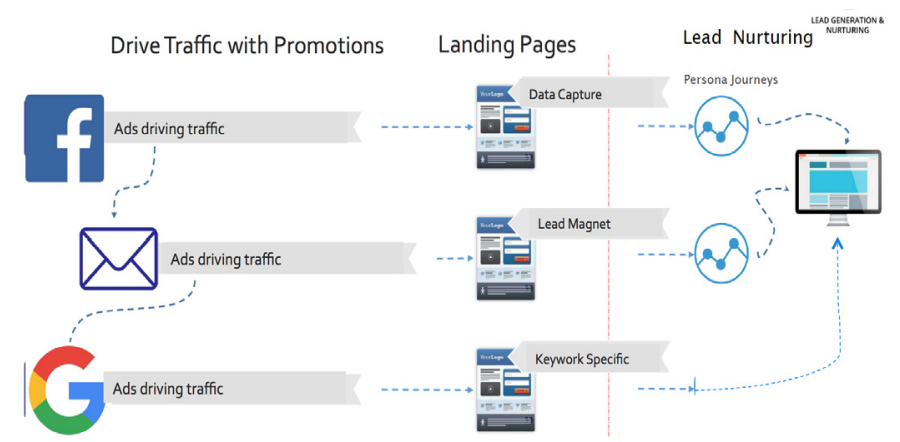

Figure 3: Driving Customer Traffic from Promotions and Social Media to One's Home (or Landing Page) (Image Courtesy of Randy Gerson and Chris dEon, Gerson and Associates, 2018) [8].
Katheryn Gorges, a Northern-California marketing consultant who teaches at the University of California, Berkeley (UCB), emphasizes the optimization of the site for SEO, and usability [5]. She points out in her marketing strategies for entrepreneurs and small business owners' class at UCB that the home or landing page needs to be simple, include a clear hero image that represents the brand experience, and provide multiple calls to actions that are clearly defined so the customer can find them easily. She also advocates placing a section with one's current blogs on the home page, even if it is below the fold, and have links to relevant archived content.

Furthermore, Jennifer Tomlinson, Sr. Marketing Manager of Microsoft's Partner Network, points out several key pieces in her article, 10 Ways to Create a Customer-Centric Website [9]. Several items of these recommendations resonate with and add to my earlier observations in this article. First, she indicates that one should begin with a modern web platform. This point ties into my previous comments related to site architecture. In addition to fulfilling functional aspects, such as load-time responsiveness, mobile friendliness, and built-in SEO assistance, one needs to consider the site aesthetics since an unappealing site may translate into a high bounce rate. Second, she advises that one should make the site easy to navigate and test it out with someone not familiar with it. It needs to be clear for every stage of the customer journey by providing information, white papers, case studies, and testimonials as required. Third, she adds that one should make it easy for customers to reach the firm. Make sure that they can get the right contact information. Fourth, she builds on the last point by advising that one provide customer support information (these items should be consistent across all digital and social platforms). More sites are offering an assistant or bot to help the customer with the interaction. Fifth, she advises that one use the customer's information to his/her benefit. Make it easy to fill in information and, if the customer has done so already, have a mechanism to "Pull" that information into other required fields. Make the customer journey easy so don't make them fill in multiple forms many times over. Sixth, she recommends that one follow up the customer visiting your website. Personalize the contact and do it in a timely fashion, either by phone or via email with a relevant offer [3].

The final argument supporting the need for a more customercentric website comes from Scott [3]. First, he relates to the customer journey and makes sure one provides appropriate content links to guide the customer along. One needs to understand the customer. Second, he points out that a company should have a distinct, consistent, and memorable site. The homepage should be consistent with the company's personality. For example, he illustrates this point with the discussion of how HotforSecurity site fulfills these criteria. Third, he advises that one use photos and images to tell the story. Fourth, he suggests that one should use 
include interactive tools (e.g., stock quotes, mortgage quotes). My students in my social media class recommended such for their client, California Closets, to make the company's site more engaging to the millennial audience. Fifth, he suggests that one should create feedback loops for the customer to contact one's company and customer service. Sixth, he notes that one should provide other ways for your customers to interact with each other. Highlighting customer stories or contacting a happy owner of your company's product is an excellent way to create greater engagement. Seventh, he adds that one should keep the site current, which is critical for SEO. Eighth, he advises to include social media sharing buttons so customers can share content, and especially your videos, white papers, and blogs. Ninth, he points out about the considering the customer's preferred media and learning styles. Tenth, he recommends creating content with a pass-along value that could go viral: humor or something catchy such as Psy's Gangnam style dance or a fantastic event, such as Felix Baumgartner's worldrecord skydive sponsored by Red Bull. With such content, make sure one's URLs are permanent, so one's customers do not end up with a dead end. Eleventh, he highlights the need to make sure one has an easy-to-use mechanism linked directly from the content to close out the purchase and that that one streamlines purchase process so that it is no more than a click (or two at most) away.

Finally, Scott points out the need for requiring a "call-toaction" sign up for the customer to obtain free content such as a white paper [3]. I know that "call-to-action" buttons are critical for tracking engagement and metrics [3]. However, what I found fascinating and very customer centered was his discussion around an open-source marketing model. In the example with concrete, he illustrates the provided the download "free" without a signup. It led to more downloads and engagement by customers and a community of customers to pass along with content, and free working models. He added that this practice could be followed up later by the returning prospect with a sign up for a further interaction of content piece [3]. This point is quite relevant as customers become more ever concerned with their privacy, hacking of customer lists, and the reselling of their information. This point provides an excellent example of building a trusting and permissive relationship. It shows how in building trust one can expand its reach and monetize the relationship with add-on enhancements and tools. This strategy is one that the gaming industry uses quite effectively as well.

\section{Influencing the Buying Process}

\section{(Back to the Customer Journey)}

The final area of this discussion circles back to my earlier point about the customer journey. The design of the website's content, organization, and functionality of the site to keep this in mind. Smart strategic marketers understand this concept and that of the marketing funnel: awareness, information, decision, and acquisition (AIDA) (Table 2, Figure 4). It is time and again something that I use and teach to my students in my social media, marketing projects, and marketing management classes.

\begin{tabular}{|c|c|c|}
\hline Step & Stages & Tactical Examples \\
\hline & & Customer testimonies \\
1 & $\begin{array}{c}\text { Awareness } \\
\text { and } \\
\text { Information } \\
\text { (AI) }\end{array}$ & Links from other sites \\
& SEO optimization \\
& & Short videos \\
2 & Decision (D) & Social media redirects (via links) \\
& & Whitepapers \\
\hline 3 & Acquisition & Free trial \\
& (A) & Retargeting follow up \\
& & Clear "call-to-action" buttons \\
& & Consultation request \\
& & Contact us \\
& & Newsletter or webinar signup \\
& & Website attendant \\
\hline
\end{tabular}

Table 2: Influencing the Marketing Funnel Buying Process (AIDA) via a Customer-centric Website [3].

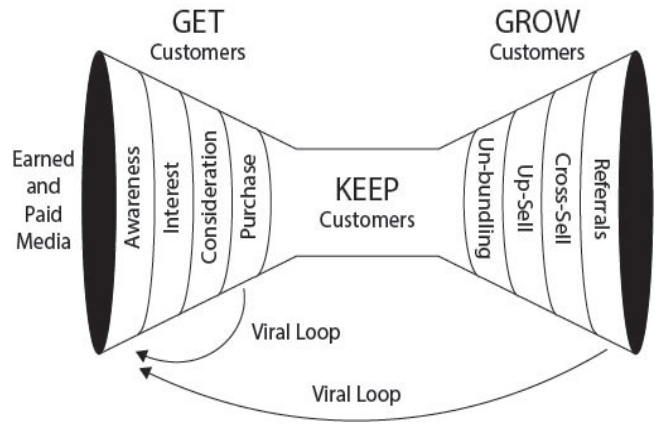

Figure 4: Get, Keep and Grow Marketing Funnel [7].

Scott emphasizes the importance of this process and outlines it with several steps [3]. He notes that successful sites need to draw customers into the sales cycle. Therefore, Step 1, involve them with informational content to move the buyer into the funnel through "A" for awareness and "I" for information/education. This aspect I have discussed in detail in rationale and SEO sections of this paper. The two points to take away here include: (1) the customers have to find you, so you have to have relevant content, keywords, links, and SEO-friendly architecture; and (2) the material in the site needs to be relevant, easily accessible, and supportive to the journey. Taking this thought further, one needs to content needs to be linked to relevant "call-to-action" buttons, and 
more specifically to the point where the customer can seamlessly make the purchase.

The marketer needs to keep in mind that customer may be considering alternatives options during this informational phase so heavy-handed tactics should not be used to close the customer here. However, with some customer information gained, either directly or via cookies, the market can reach out to the customer either as a follow up with a phone call or an email message with a relevant offer such as a discount coupon or a free month trial. Sometime the customer may need some time. From a discussion with the social media manager in one of my clients, she noted that this national firm, similar to others, is now investing heavily in retargeting of these prospects since these leads might have just been in the early stages of the journey and just need a friendly nudge anywhere from a few days to two weeks later [10].

In Step 2, Scott points out that sometimes the customer needs a friendly nudge [3]. He adds that once the company has established a relationship and trust, and its expertise in the category and knowledge in solving the customer's problem, now it has earned the right to introduce the product or service. In the process, it is essential to focus on the buyer and his/her problems, rather than the competition. In this phase, one may be asking for information and need to provide something valuable in return, such as a webinar or white paper. As the buyer gets into the " $\mathrm{D}$ " a phase of the journey, he/she might have questions and is seeing how responsive the firm is to these queries. The customer may have some needs to sample or try out the product. Again, the website should support this step in the process. This trial strategy is used very effectively with cloudbased software programs. For example, I needed to use a statistics package last fall and researched a few options. I ended up with a GraphPad trial with some technical support. Next thing I know I am using the software regularly and am glad to pay for a yearly subscription. The bottom line in the process is to be responsive to the customer and make him/her think that you are sensitive to him/ her and his/her needs.

Finally, there is Step 3. Per Scott, this stage involves closing the deal or the "A" for acquisition [3]. Having "buy buttons" or "call-to-action" buttons and tying them with every page are essential [3]. This point is something that Lorrie Thomas highlights in her book, The McGraw-Hill 36-Hour Course: Online Marketing [6]. Gorges adds that when marketers design a website, they need to think the journey from all aspects [5].

Most importantly, they need to have clear "call-to-action" buttons linked to all pages. Gerson and d'Eon also emphasize this point in their lections on website content as well [8]. Scott points out that that the marketer needs to have multiple ways for buyers to express interest [3]. One way is the purchase now button if this is an online product. Start a free trial. Other ways can be via a "contact us" or "request a consultant or sales person call." Usually, marketers use this approach with higher ticket items. For instance, California Closets uses to request a "free design consultation."

\section{Closing the Circle of the Customer-Centric Website and the Customer Journey}

I developed this piece to explore the evolving digital strategy for entrepreneurs, small firms, and marketers. The understanding o changing dynamics of social media and digital marketing is essential in today's marketplace. The Internet and social media have changed the way marketers are engaging (and needing to engage) with their customers. Some continue to remain with "Push, Push, Push," as part of their interruptive marketing approach. This approach might be acceptable for some media such as a television in reaching a broad audience and wanting to deliver a specific message. However, the rules have changed on the Web.

The customer has replaced these rules through the technologies they use, the platforms they interact with, and their new buying behaviors [11-18]. Customer centricity is essential to a website. It needs to make the customer journey easy and a positive one. These considerations are critical to designing permissive content to attract, to engage, to support information/education needs, to dialogue with other customers, to engage the company (and to get a rapid response before, during, and after the sales), and an accessible path to acquisition. Hence, the strategy behind digital needs to support this approach and the features and functionality of the website needs to help support this process. If a marketer can do this effectively, one can increase traffic, improve the efficiency of the funnel (speed of the customer journey), utilize resources more efficiently (and effectively), build repeating relationships, and enhance customer loyalty, as is seen with companies such as Zappos or Amazon. These are the new rules for the game that smart marketers need to play to be successful.

\section{References}

1. Customer-centric. Business Dictionary com.

2. Kroner E (2018) The 7 Pillars of Customer Centricity. American Marketing Association 2018.

3. Scott DM (2015) The New Rules for Marketing and PR. Hoboken, NJ. John Wiley and Sons, Inc 2015.

4. Gardner J, Cooper B (2014) The Lean Brand. San Diego, CA. Market by Numbers 2014.

5. Gorges K (2016) Website lecture on Marketing Strategies for Entrepreneurs and Small Businesses 2016.

6. Thomas L (2011) The McGraw-Hill 36-Hour Course: Online Marketing. New York, NY. McGraw-Hill 2011.

7. York JM (2018) Putting Lean Startup into Perspective: A Novel Approach for Discovering and Developing a Successful Business Model. Arch Bus Adm Manag 2018. 
Citation: York JM (2018) A Digital Strategy for Enhancing the Customer Journey via a Customer-Centric Website. Arch Bus Adm Manag: ABAM-122. DOI: 10.29011/ ABAM-122. 100022

8. Chris d'Eon. C, Gerson R (2018) Invited Lecture on Content Marketing. Orfalea College of Business, San Luis Obispo, CA 2018.

9. Thomlinson J (2016) 10 Ways to Create a Customer-Centric Website. Microsoft Partner Network 2016.

10. Gains T (2018) Personal communication. California Closets 2018.

11. Court D, Elzinga D, Mulder S, Vetvik OJ (2009) The customer decision journey. McKinsey Quarterly. No 3.

12. Dragilev C (2016) Entrepreneur: Here's What Really Matters for SEO in 2016.

13. Ivanov AE (2012) The Internet's Impact on Integrated Marketing Communications 3: 536-542.
14. Mihaela OOE (2015) The Influence of Integrated Marketing Communications on Consumer Buying Behavior. Procedia Economics and Finance 23: 14461450 .

15. White RL [n.d]. How the marketing funnel works from top to bottom. Track Maven.

16. York JM (2018) Getting a clear strategic picture with IMC and Social Media. Orfalea College of Business 2018.

17. York JM (2018) SEO and a Little More. B459 Lecture. Orfalea College of Business 2018.

18. Evans B (2013) Customers Don't Want Ads; They Want a Conversation. Fast Company 2013. 